\title{
Development and Application of Molecular Tagging Velocimetry for Gas Flows in Thermal Hydraulics
}

\author{
Matthieu A. André, ${ }^{\mathrm{a}, *}$ Ross A. Burns, ${ }^{\mathrm{b}}$ Paul M. Danehy, ${ }^{\mathrm{c}}$ \\ Seth R. Cadell, ${ }^{\mathrm{d}}$ Brian G. Woods, ${ }^{\mathrm{d}}$ and Philippe M. Bardet ${ }^{\mathrm{a}}$ \\ ${ }^{a}$ The George Washington University, Department of Mechanical and Aerospace Engineering \\ Washington, DC 20052 \\ ${ }^{b}$ National Institute of Aerospace \\ Hampton, VA 23666 \\ ${ }^{c}$ NASA Langley Research Center \\ Hampton, VA 23681 \\ ${ }^{d}$ Oregon State University, Department of Nuclear Engineering \\ Corvallis, OR 97331 \\ *Email: matandre@gwu.edu
}

Number of pages: 19

Number of tables: 1

Number of figures: 6 


\begin{abstract}
Molecular tagging velocimetry (MTV) is a non intrusive velocimetry technique based on laser spectroscopy. It is particularly adequate in challenging gas flow conditions encountered in thermal hydraulics where particle-based methods such as particle image (or tracking) velocimetry do not perform well. The main principles for designing and operating this diagnostic are presented as well as a set of gases that have been identified as potential seeds. Two gases $\left(\mathrm{H}_{2} \mathrm{O}\right.$ and $\left.\mathrm{N}_{2} \mathrm{O}\right)$ have been characterized extensively for thermodynamic conditions ranging from standard temperature and pressure to environments encountered in integral effect test (IET) facilities for high temperature gas reactors (HTGR). A flexible, modular, and transportable laser system has been designed and demonstrated with $\mathrm{H}_{2} \mathrm{O}$ and $\mathrm{N}_{2} \mathrm{O}$ seed gases. The laser system enabled to determine the optimum excitation wavelength, tracer concentration, and timing parameters. Velocity precision and thermodynamic domain of applicability are discussed for both tracers. The spectroscopic nature of the diagnostics enables to perform first principle uncertainty analysis which makes it attractive for validating numerical models.

MTV is demonstrated for two flows. First, in blow down tests with $\mathrm{H}_{2} \mathrm{O}$ seed, the unique laser system enables one of the largest dynamic ranges reported to date for velocimetry: 5,000:1 (74 dB). $\mathrm{N}_{2} \mathrm{O}-\mathrm{MTV}$ is then deployed in-situ in an IET, the high-temperature test facility at Oregon State University during a depressurized condition cooldown (DCC) event. Data enable to gain insights into flow instabilities present during DCC. Thus, MTV shows a strong potential to gain fundamental understanding of gas flows in nuclear thermal hydraulics and to provide validation data for numerical solvers.
\end{abstract}

Keywords - Molecular tagging velocimetry, high dynamic range, gas flow thermal hydraulics 


\section{INTRODUCTION}

Gas flows are commonly encountered in nuclear thermal hydraulics and can be challenging to instrument, particularly for measuring velocity. Examples of gas flows include containment studies [1], steam flow during reflood (liquid cooling after loss of coolant accident) of pressurized water reactor (PWR) fuel bundles [2], or high temperature gas cooled reactors (HTGR) [3]. Velocimetry methods that rely on Mie scattering of solid particles to seed the flow (such as particle image or tracking velocimetry or laser Doppler velocimetry, PIV, PTV, or LDV, respectively) have been demonstrated successfully for some instances [1]. However, conditions such as accident scenarios in HTGR can involve very high speed flows (blow down), very high temperature (pressurized conduction cooldown), or very slow transients (depressurized conduction cooldown or DCC); the inertia and buoyancy of particles will preclude them from accurately seeding the flow. Additionally, in PWR reflood liquid water flashes to steam; the steam flow cools the fuel bundles in a process that needs to better understood. Seeding the steam with particles could be challenging; one possibility would be to add particles to the liquid water and hope that sufficient particles are entrained in the steam following the phase change. Also for some of these flows the speed is low and the particles may settle out. Non-particle-based laser spectroscopy techniques such as molecular tagging velocimetry (MTV) could address some of these limitations.

MTV is a time-of-flight velocimetry method that relies on locally creating and tracking molecular tracers [4]. This non-intrusive technique is applicable to a wide variety of gas and liquid flows ranging from stagnant to hypersonic, from cryogenic to flame temperature, and over a large range of pressure.

The instrument most commonly uses two sets of lasers. A first (write) laser creates tracers with a predetermined spatial pattern, and then a second (read) laser illuminates a cross-section of the flow within a controlled time interval $d t$ and excites the fluorescence of tracers "written" in the gas. The location of the displaced tracers is recorded for each read pulse with a camera, ultimately leading to velocity fields. In gases, tracers are typically created through photo-dissociation of specific seed molecules and are tracked with planar laser-induced fluorescence (PLIF). MTV has been demonstrated in gas with a variety of tracers; examples of seed gas include $\mathrm{N}_{2} \mathrm{O}$ [5], $\mathrm{NO}_{2}[6]$, $\mathrm{Kr}[7]$, acetone [8], biacetyl [9], $\mathrm{O}_{2}[10,11], \mathrm{N}_{2}$ [12], or $\mathrm{H}_{2} \mathrm{O}[11,13]$. MTV based on $\mathrm{NH}$ tracers created from trace $\mathrm{H}_{2} \mathrm{O}(0.1 \%)$ or $\mathrm{H}_{2}(1 \%)$ in $\mathrm{N}_{2}$ was also recently demonstrated [14]. 
The present work focuses on two tracers that have been extensively characterized and demonstrated over a broad range of temperature and pressure relevant to thermal-hydraulics: NO and $\mathrm{OH}$ obtained from $\mathrm{N}_{2} \mathrm{O}$ (nitrous oxide) and $\mathrm{H}_{2} \mathrm{O}$ (water vapor) seed gases, respectively. The highdynamic range of the MTV system developed by the authors is demonstrated for a blow down test, and the system is also demonstrated in-situ in an integral effect test (IET) facility, the High Temperature Test Facility (HTTF) at Oregon State University (OSU).

\section{EXPERIMENTAL TECHNIQUE}

\section{II.A. Tracers selection}

The selection of appropriate tracers is the first and most important step in designing an MTV diagnostic. For a particular test condition, the tracers should have adequate chemistry and lifetimes, seeding properties, and chemical compatibilities. For instance, some seed gases such as $\mathrm{H}_{2} \mathrm{O}$ are naturally present in many environments and would be appropriate for some tests in air. However, condensation could be detrimental and in high temperature applications $\mathrm{H}_{2} \mathrm{O}$ could lead to oxidation [15]. Furthermore, $\mathrm{OH}$ radicals are highly reactive and will quickly recombine with $\mathrm{O}_{2}, \mathrm{H}$, or itself [11]. NO is stable in inert environments such as helium or nitrogen, which is useful for increasing the probe delay time to improve velocity precision for low speed flows.

\section{II.A.1. Potential tracers}

The following gases have been identified as potential traces for MTV tests in thermalhydraulics, Table I.

TABLE I

Selection of tracer/seed gas with their respective write and read laser wavelengths

\begin{tabular}{c|c|ccc} 
Seed gas & Tracer & $\begin{array}{c}\lambda_{\text {write }} \\
(\mathrm{nm})\end{array}$ & $\begin{array}{c}\lambda_{\text {read }} \\
(\mathrm{nm})\end{array}$ & Reference \\
\hline $\mathrm{NO}_{2}$ & $\mathrm{NO}$ & 355 & 226 & {$[16]$} \\
$\mathrm{N}_{2} \mathrm{O}$ & $\mathrm{NO}$ & 193 & 226 & {$[5]$} \\
$\mathrm{O}_{2}$ & $\mathrm{O}_{3}$ & 193 & 248 & {$[11]$} \\
$\mathrm{H}_{2} \mathrm{O}$ & $\mathrm{OH}$ & 193 & 282 & {$[17]$} \\
$\mathrm{Kr}$ & $\mathrm{Kr}$ & 215 & 760 & {$[7]$}
\end{tabular}

$193 \mathrm{~nm}$ is produced with an ArF excimer laser, while $355 \mathrm{~nm}$ is obtained from a frequency tripled Nd:YAG laser. The other wavelengths are obtained with tunable lasers, such as tunable dye 
lasers or optical parametric oscillators (OPO). This is covered in section II.B. Note that other read laser wavelengths, corresponding to other vibrational transitions, can be used for these tracers. These reported in the table are the most efficient and widely used. Of the five seed gases listed in table $\mathrm{I} \mathrm{H}_{2} \mathrm{O}$ and $\mathrm{N}_{2} \mathrm{O}$ have been extensively characterized by the authors and their behaviors are reported in detail below.

\section{II.A.2. Precision limits}

Temperature, pressure, tracer concentration, probe time, and working gas affect the precision that can be obtained with MTV. For tracers that are chemically inert, molecular diffusion of the tracers limits the probe time by spreading the tag line. Very diffuse lines will degrade the pattern matching between the initial and displaced lines. The diffusion of the tracers increases with $d t$ :

$$
w=\sqrt{8 \ln 2 D d t+w_{0}^{2}}
$$

$w_{0}$ is the initial width of the tracers created by the "write" pulse and $D$ is the binary diffusion coefficient of the tracer and working gas. Based on kinetic theory of gases, $D$ scales as $T^{3 / 2} / P$. Higher temperature will result in worse precision due to faster diffusion of the tracers, while high pressure environments will reduce the effect of diffusion. In particular, tracers at the conditions of scaled HTGR, such as the HTTF (1100 K and 8 atm) will diffuse less than at standard temperature and pressure (STP). The working gas will also significantly affect the diffusivity; for example the diffusivity of $\mathrm{NO}$ in $\mathrm{He}$ is nearly 7 times larger than in $\mathrm{N}_{2}$ [18].

Additionally, the signal-to-noise ratio (SNR) strongly affects the precision of the technique. SNR depends on the ability of the write beam to effectively photo-dissociate tracers. This is a function of the laser wavelength, fluence, and seed gas concentration and absorption cross-section, $\sigma$. The latter depends on pressure and temperature. For example the photo-dissociation crosssection of water vapor at $193 \mathrm{~nm}$ is nearly 40 times larger at $1000 \mathrm{~K}$ than at $300 \mathrm{~K}$.

\section{II.A.3. Laser beam absorption}

Another factor affecting SNR is the absorption of the laser beams by gases in the test section and in the laboratory. This can be particularly problematic if the write pulse loses too much energy to photo-dissociate enough tracers. The number density of photo-dissociated molecules, $n_{d}$ over a 
distance $L$, is:

$$
n_{d}=\frac{E_{\mathrm{abs}}}{h \nu A L}
$$

With $h$ Planck's constant and A the beam cross sectional area. The absorbed beam energy, $E_{\text {abs }}$, is given by a Beer-Lambert law:

$$
E_{\mathrm{abs}}=E_{0}\left(1-\exp \left(-\sigma n_{i} L\right)\right)
$$

$E_{0}$ is the initial beam energy, and $n_{i}$ is the seed gas number density. The LIF signal can be improved by increasing the seed gas concentration, however, this will also result in less energy being transmitted to the test region. Thus the optimal concentration of seed gas is a trade-off involving the beam path length in the test section, $L$, and is given by $1 /(\sigma L)$. For distance longer than $0.5 \mathrm{~m}$ at STP, $\mathrm{N}_{2} \mathrm{O}$ concentration should be less than $1 \%\left(\sigma=9 \times 10^{-20} \mathrm{~cm}^{2}\right) . \mathrm{H}_{2} \mathrm{O}$ is relatively unaffected by this constraint as its absorption cross-section is two orders of magnitude lower than that of $\mathrm{N}_{2} \mathrm{O}$ at STP $\left(\sigma=8 \times 10^{-22} \mathrm{~cm}^{2}\right)$. For instance, beam absorption by $3 \% \mathrm{H}_{2} \mathrm{O}$ would become an issue only for path length exceeding $10 \mathrm{~m}$. Note that since $\sigma$ depends on pressure and temperature, this constraint will change accordingly to the test conditions.

In addition to the gases in the test section, gases outside of the test section can significantly absorb laser light. For example at $193 \mathrm{~nm}$, oxygen absorbs and the write beam is significantly attenuated in the laboratory. This can be remedied by enclosing the beam in a tube and purging the air from the tube with an inert gas like $\mathrm{N}_{2}$.

Finally, UV light is absorbed by common transparent glass materials used in viewports or prisms, which results in reduced energy being delivered to the test section. Optical components must be selected carefully.

\section{II.A.4. Chemical compatibility}

A non-negligible factor in selecting tracers is the chemical compatibility with the materials of the test section. For example, $\mathrm{NO}_{2}$ is very aggressive with corroding most gasket materials or acetone could irreparably damage plastic components. Additionally, some seed gases are toxic and appropriate procedures must be deployed to protect the operators. Finally, some seed gases can be prohibitively expensive for large facilities. 


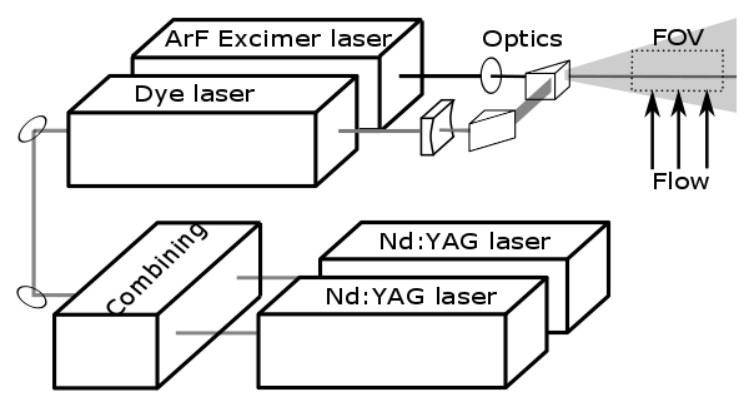

Fig. 1. Diagram of the MTV system. The flow is imaged in the field of view (FOV) shown in dotted rectangle

\section{II.B. MTV system}

The instrument used here relies on several lasers and a camera synchronized together at 10 Hz. The seed gas is initially dispersed in the flow being probed. A first laser beam (the write pulse) is from an excimer laser (GAM Laser EX5) at $193 \mathrm{~nm}$ and creates the tracer molecules (OH or NO) nearly instantaneously ( $\approx 10 \mathrm{~ns}$ ) along its path. Two laser pulses shaped in a 3 -mm thick sheet (read pulses) are then emitted from a tunable dye laser (Sirah Cobra-Stretch pumped by two Nd:YAG lasers) to illuminate the tracers and induce fluorescence. An intensified camera (QImaging QIClick CCD camera coupled with a LaVision IRO intensifier) records the fluorescent signal and rejects the laser light (282 or $226 \mathrm{~nm}$, depending on tracer selection) with a suitable long-pass filter, measuring on the location of the tracers at two different instants in time. Figure 1 shows the spatial arrangement of the lasers. The velocity is then obtained by measuring the displacement using cross-correlation techniques and knowing the delay between the two images. Since only a single tag line was used in this study, only a single component of velocity can be resolved. Finally, the system is transportable and can be deployed in laboratories of collaborators in a time and cost effective manner.

\section{II.C. Test sections}

A stainless steel pressure vessel was built to investigate in a laboratory the performance of the diagnostics in conditions as encountered in a HTGR - namely high pressure and high temperature. The test section, shown schematically in figure 2 left, is fitted with two UV-transparent fused-silica viewports to allow the laser beams to enter and the fluorescence signal to be captured. A $9.0 \mathrm{~mm}$ 


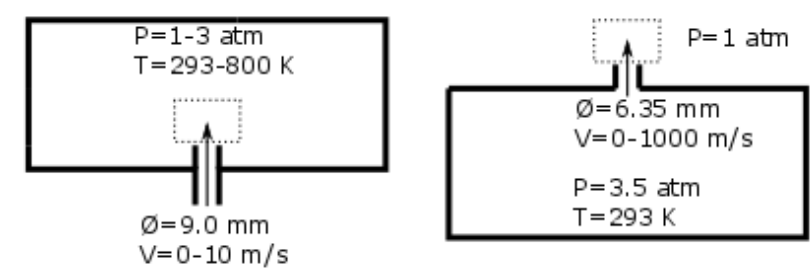

Fig. 2. Schematic of the test section for: -pressure and temperature tests (left) and -velocity dynamic range (right). The arrow shows the flow direction, and the dotted rectangle shows the field of view.

diameter jet discharges vertically in the section to generate a well-controlled flow of nitrogen or helium containing a small fraction of seed gas that can be probed with MTV. A computerized data acquisition system controls and monitors pressure and temperature in the chamber, as well as jet flow rate and seed gas injection rate.

A second test section, shown in figure 2 right, was assembled to investigate large velocity ranges. It consists of a 5.7 liter vessel that can be pressurized and then vented to the atmosphere to create a choked flow at the jet exit. The velocity can range from sonic speed to zero.

\section{RESULTS}

\section{III.A. Tracer spectra and wavelength selection}

The fluorescence excitation spectrum of each tracer is first measured and analyzed to identify the optimum wavelength for the dye laser (read pulse). The MTV signal is recorded while the dye laser scans the wavelength, and all other parameters (laser power, seed gas concentration, probe time) are held constant. Spectra for $\mathrm{OH}$ and $\mathrm{NO}$ are presented in Figure 3 at ambient temperature and pressure. The respective spectra computed with the software LIFBASE [19] are also plotted on these figures and show a good agreement with the experimental data. The strongest signal (highest peak) is obtained at a wavelength of $281.905 \mathrm{~nm}$ and $226.186 \mathrm{~nm}$ for $\mathrm{OH}$ and $\mathrm{NO}$, respectively.

Tests were also performed at higher pressure (up to $3 \mathrm{~atm}$ ) and temperature (up to $800 \mathrm{~K}$ ). While pressure and temperature affects the peak height and width through collisional quenching and broadening, the best signal was still obtained at the same wavelength, which ensures the dye laser would not need to be tuned for changing pressure or temperature. 

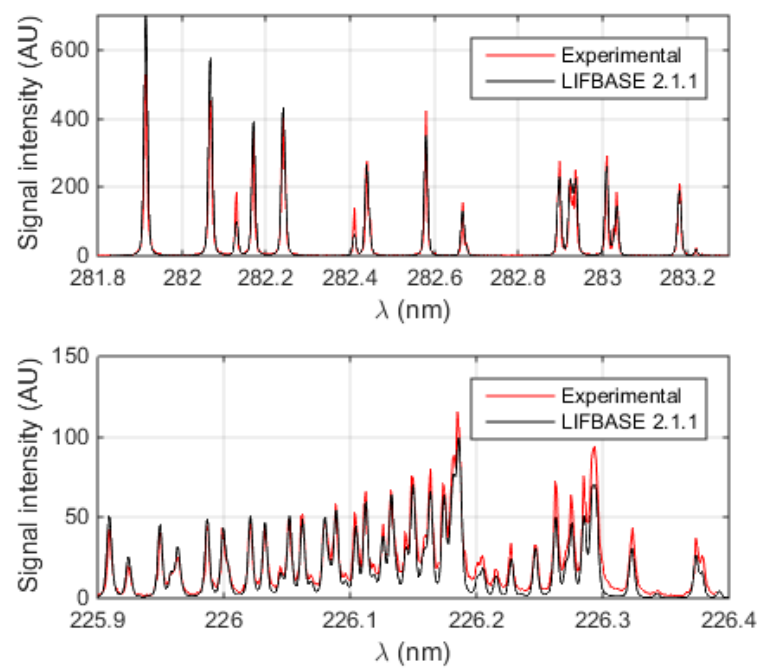

Fig. 3. $\mathrm{OH}$ (top) and $\mathrm{NO}$ (bottom) excitation spectra at ambient pressure and temperature. Experimental data are compared to simulations by the software LIFBASE.

\section{III.B. Effect of temperature, pressure, probe time, and seed gas concentration}

For the data described in this section the fluorescence signal is measured by keeping the wavelength of the read pulse constant (where the signal is maximum) while the temperature, pressure, and seed gas concentration are varied. The tracers are probed at various times after being created by the write pulse. Detailed results for $\mathrm{OH}$ and NO tracers can be found in [13] and [18], respectively. The main findings are summarized here.

\section{III.B.1. OH tracers}

The signal from $\mathrm{OH}$ tracers improves with increasing temperature (higher $\mathrm{H}_{2} \mathrm{O}$ photodissociation efficiency), and deteriorates with an increase in pressure due to collisional quenching of fluorescence. $\mathrm{OH}$ recombination also increases with pressure.

The seed gas concentration is based on equilibrium with vapor pressure of water at a given pressure and at ambient temperature. This corresponds to $2.7 \%$ and $0.9 \%$ molar at 1 and $3 \mathrm{~atm}$, respectively.

Probe time measurements ranged from $5 \mu$ s to $6.4 \mathrm{~ms}$. At short $d t(<100 \mu \mathrm{s})$, the signal decreases with an increase in $d t$, approximately following a $1 / \sqrt{d t}$ trend. This decrease in signal is attributed to the recombination of $\mathrm{OH}$ with itself and other photo-products. Chemical reac- 
tion simulations conducted with the code Cantera [20] confirmed the observed decay rate of $\mathrm{OH}$ molecules. Above $3 \mathrm{~ms}$, the signal-to-noise ratio (SNR) becomes too low to precisely measure the tracers location. Therefore this limits the precision that can be achieved with this tracer in these conditions, as discussed in Sec. III.C.

\section{III.B.2. NO tracers}

The effects of pressure and temperature on the signal of NO tracers are qualitatively similar to that of $\mathrm{OH}$, for similar reasons.

The seed gas concentration $\left(\mathrm{N}_{2} \mathrm{O}\right)$ is varied from 0.1 to $6 \%$ molar. The signal increases with concentration for low concentration $(<2 \%)$. The SNR then plateaus or decreases between 2 to 4\%. This effect is caused by the attenuation of the write beam on its path to the measurement region. For high seed gas concentration, the write beam will be strongly absorbed before it reaches that region.

Probe time of $\mathrm{NO}$ can be extended to tens of milliseconds due to its low reactivity in inert gases. The limiting factor to increasing $d t$ is tracer diffusion, which becomes significant around 10 to $40 \mathrm{~ms}$ for helium and nitrogen flow, respectively.

\section{III.C. Velocity measurement precision}

MTV is a time-of-flight technique, and the velocity is obtained by measuring a displacement over a period of time according to the equation $V=M \Delta x / d t$ with $M$ the image magnification, and $\Delta x$ the measured tracer displacement in pixels. Since the measurement resolution of the displacement is limited by the camera resolution (discretized in pixels), larger $d t$ are required to probe slower flows for a given magnification $(0.137 \mathrm{~mm} /$ pixel for the present experiments). The precision of the velocity measurement is approximated by $\sigma_{v}=M \sigma_{x} / d t$, in which the precision on the measured displacement, $\sigma_{x}$, is a function of the camera, optics, and processing algorithm, as well as signal quality (typically characterized by the SNR). Comparison of the precision of the measurements obtained with $\mathrm{OH}$ and $\mathrm{NO}$ is presented in figure 4 at ambient temperature and pressure. At short $d t, \mathrm{OH}$ has a better precision (smaller standard deviation), however, this is a consequence of the higher SNR resulting from higher seed gas concentration $\left(2.7 \%\right.$ for $\mathrm{H}_{2} \mathrm{O}$ versus $0.5 \% \mathrm{~N}_{2} \mathrm{O}$ ), as well as higher read pulse energy (10 mJ versus $\left.4 \mathrm{~mJ}\right)$. 


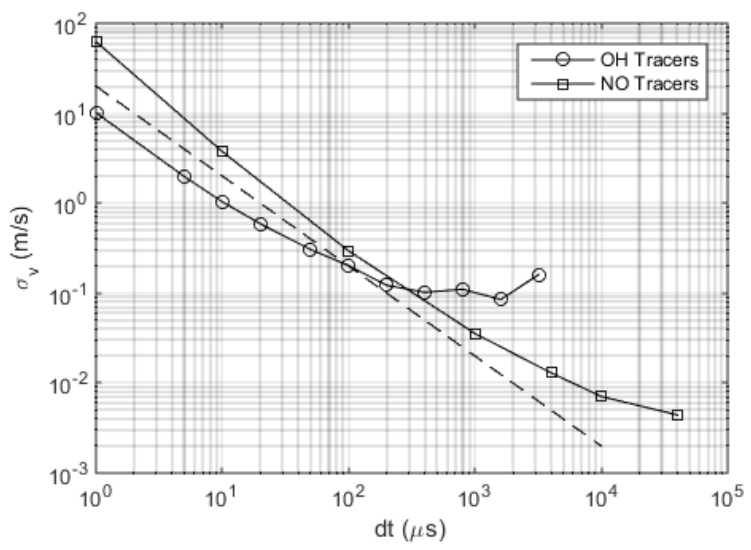

Fig. 4. Comparison of precision of the velocity data obtained with $\mathrm{OH}$ and $\mathrm{NO}$ tracers as function of the probe time delay

As $d t$ is increased, the precision improves (i.e. standard deviation decreases) for both tracers, following the theoretical $1 / d t$ trend (dashed line). The precision with $\mathrm{OH}$ tracers then plateaus at about $0.1 \mathrm{~m} / \mathrm{s}$ around $d t=1 \mathrm{~ms}$ due to recombination of the tracers. Signal is then completely lost above $3 \mathrm{~ms}$. NO tracers are more stable and can be probed over longer $d t$, thus improving the precision. The best precision with NO tracers in the present measurements is $0.004 \mathrm{~m} / \mathrm{s}$ at $d t=40 \mathrm{~ms}$. At longer $d t$ the gain in precision is only marginal due to the molecular diffusion of the tracers spreading the tag line.

\section{III.D. Velocity dynamic range}

Molecular tracers are well suited for probing low speed flows due to the absence of settling. They also perform very well for high speed and acceleration flows thanks to their perfect frequency response (no inertia lag). However, time-of-flight methods such as PIV or MTV are usually limited in term of velocity dynamic range by the measurement accuracy of the tracer displacement (usually 0.2 to 0.5 pixels for MTV, depending on the SNR). To maintain a reasonably good spatial resolution and resolve local (instead of spatially averaged) velocity, a maximum acceptable tracer displacement must be set, typically less than 100 pixels. This results in a velocity dynamic range typically on the order of $10^{2}$. There exists various methods to increase this range with PIV such as multi-grid interrogation, and multiple exposure recording. For MTV with a single tag line, only the latter is possible, but requires several read laser pulses. 
The majority of MTV studies to date have used only one read pulse. The initial location of the tracers is recorded in a separate step by firing the read pulse within a few nanoseconds of the write pulse. The assumption that the initial location of the tracers is constant is reasonable when doing measurements in tabletop experiments, where the environment is well controlled. Factors potentially affecting the position of the write beam are vibrations, beam pointing stability, beam steering through turbulent flow and thermal expansion. Therefore, it is preferable to rely on two probe beams (read pulses) when doing field measurements where such issues may occur, as done in the present work.

In more controlled experiments where the initial tracer location is constant, the two probe pulses can be taken advantage of to increase the velocity dynamic range. For instance, a first pulse can be fired after a short delay, allowing measurement of high speed flows, and then a second pulse is fired after a longer time, enabling the measurement of lower velocities. The dynamic range of this MTV scheme was investigated with $\mathrm{OH}$ tracers. The tests were performed in the test section shown in figure 2 right, pressurized with helium at 3.5 atm and with a small amount of liquid water to seed the gas flow with vapor in equilibrium condition. NO tracers would work as well based on the above results.

At the beginning of the test, a valve is quickly opened to vent the chamber to the atmosphere. Such flow would be similar to a blowdown, as is experienced during the depressurization phase of a DCC. Velocity is measured with MTV at the valve exit. The first read pulse is $3 \mu$ s after the write pulse and is used for resolving high speed flow $(O(100) \mathrm{m} / \mathrm{s})$. For low flow speed $(O(1) \mathrm{m} / \mathrm{s})$, the displacement after $3 \mu \mathrm{s}$ is very small, and the relative precision is poor. The lower speed phase of the flow is more precisely resolved with a longer $d t$ of $253 \mu \mathrm{s}$. The initial tracer location is obtained from measurements before the opening of the valve, when the flow is quiescent and the line is not convected.

The time history of the jet centerline velocity is plotted in figure 5, using a logarithmic scale for the velocity axis. Before the valve opens at $t=1.5 \mathrm{~s}$ the quiescent flow is measured with the second $d t=253 \mu$ s pulse. At the valve opening, the flow is initially choked (at Mach 1 , with the speed of sound $c=1,007 \mathrm{~m} / \mathrm{s}$ for helium at $293 \mathrm{~K}$ ), and is correctly captured by the first $d t=3 \mu \mathrm{s}$ pulse. Data for the second $d t=253 \mu$ s pulse are not shown because the signal is outside of the camera field of view (and would probably be too smeared by the turbulent flow to be resolved). 


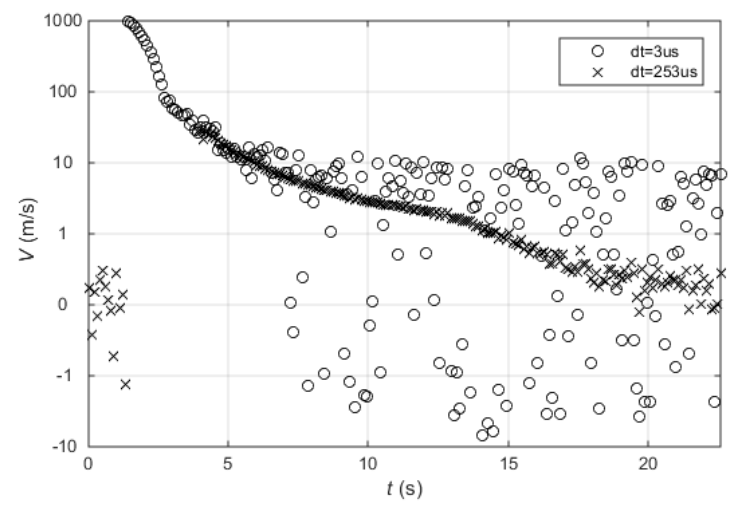

Fig. 5. Jet center velocity versus time for a helium blowdown. Velocity scale is logarithmic. Negative values of velocity are accounted by plotting $\operatorname{sign}(V) * \log |V|$

When the flow is slow enough (less than $20 \mathrm{~m} / \mathrm{s}$ ), the second pulse becomes visible and is then used to measure the velocity. The image of the first pulse is still visible (o symbols in figure 5), but the very small displacement makes the measured velocity very imprecise (on the order of $\pm 10 \mathrm{~m} / \mathrm{s}$ ). The precision with the second pulse measurement is about $0.2 \mathrm{~m} / \mathrm{s}$. Overall, the flow is resolved from $1,000 \mathrm{~m} / \mathrm{s}$ down to $0.2 \mathrm{~m} / \mathrm{s}$, which corresponds to a dynamic range of $5,000: 1$, versus about 100:1 using a single pulse. To the authors' knowledge this is the highest reported dynamic range for MTV. Theoretically, the dynamic range could be increased to $100^{2}$, however, it was chosen to have some overlap in the range 10 to $20 \mathrm{~m} / \mathrm{s}$ to ensure good continuity of the velocity time history.

Uncertainties due to calibration and timing are small compared to the displacement precision, thus the aforementioned measurement precision provides an estimation of the overall uncertainty, i.e. $10 \mathrm{~m} / \mathrm{s}$ for $d t=3 \mu \mathrm{s}$ and $0.2 \mathrm{~m} / \mathrm{s}$ for $d t=253 \mu \mathrm{s}$.

\section{IV. $\mathrm{H}_{2} \mathrm{O} / \mathrm{N}_{2} \mathrm{O}$ COMPARISON, AND APPLICABILITY TO NUCLEAR THERMAL- HYDRAULICS EXPERIMENTS}

\section{IV.A. Seed gas requirements and performances}

- $\mathrm{H}_{2} \mathrm{O}$ : The lifetime of $\mathrm{OH}$ formed from $\mathrm{H}_{2} \mathrm{O}$ is about $1 \mathrm{~ms}$ in inert environments. The signal is the strongest at short $d t(<500 \mu \mathrm{s})$ which limits the applicability of $\mathrm{OH}$ in term of minimum resolvable flow velocity (for a given magnification).

Typical molar ratio of $\mathrm{H}_{2} \mathrm{O}$ seed gas in the literature is $1 \%$ [21] and $2.8 \%$ [17]. In our 
experiments, it was $2.7 \%$ at $1 \mathrm{~atm}$, and $0.9 \%$ at $3 \mathrm{~atm}$. For reference, $3 \%$ seeding at ambient conditions corresponds to $22 \mathrm{~g} / \mathrm{m}^{3}$. Injection of seed gas can be done by adding a measured mass or volume of liquid water. Some facilities also have water vapor (or humidity) naturally occurring, and thus may not require additional seeding.

As discussed in Sec. III.B.2 related to the write beam absorption, $\mathrm{H}_{2} \mathrm{O}-\mathrm{MTV}$ (or HTV) can be deployed in facilities where the beams have to travel large distances (several meters) inside the test section, or where the seed gas content is high. In fact, HTV can be deployed in pure steam environment. For example at $1 \mathrm{~atm}$ and $500 \mathrm{~K}$, only $50 \%$ of the write beam is absorbed within the first $30 \mathrm{~cm}$, which may be sufficient for some geometries.

- $\mathrm{N}_{2} \mathrm{O}$ : $\mathrm{NO}$ formed from $\mathrm{N}_{2} \mathrm{O}$ has a relatively long lifetime; a measurable signal can be obtained at $d t$ up to tens of milliseconds which makes $\mathrm{N}_{2} \mathrm{O}-\mathrm{MTV}$ an ideal technique for probing low speed flows.

$\mathrm{N}_{2} \mathrm{O}$ has been used at molar ratio of $4 \%$ in the literature [5]. Our experiments showed that $0.5 \%$ is sufficient to get an adequate signal. For $0.5 \% \mathrm{~N}_{2} \mathrm{O}$ at ambient $P$ and $T$, this corresponds to $9 \mathrm{~g} / \mathrm{m}^{3}$. $\mathrm{N}_{2} \mathrm{O}$ gas seeding can be controlled with a mass flow meter, or by monitoring the increase in pressure during injection in a close vessel. For instance, a seeding of $0.5 \%$ can be achieved by injecting seed gas until the pressure increases by $0.5 \%$. The vessel can then be mixed and vented to the required test pressure.

The high absorption of the write beam by $\mathrm{N}_{2} \mathrm{O}$ limits the distance the beam can travel inside the facility before reaching the test section. For $0.5 \% \mathrm{~N}_{2} \mathrm{O}$, a maximum distance (resulting in $90 \%$ beam attenuation) is about 2 meters. This limitation could still be circumvented by adding a purged beam tube inside the facility. Distances can also be increased with higher power lasers resulting in more energy remaining for the measurement.

As discussed in Sec. III.D, both tracers are suitable for high speed flows since they perform well at short $d t$. Furthermore, over short distance, the seed gas concentration can be increased to improve the signal strength. The photo-dissociation process requires a similar amount of energy from the write beam for a given test condition. Finally, both seed gases are safe for humans to handle and readily available. 


\section{IV.B. Compatibility with facility components}

- $\mathrm{H}_{2} \mathrm{O}$ : It is possible that $\mathrm{H}_{2} \mathrm{O}$ could condense to liquid water inside the facility. This could present risks of oxidation, and could create short-circuits if electric components (e.g. heaters) are affected.

Graphite oxidation has been reported by gaseous $\mathrm{H}_{2} \mathrm{O}$ at ambient pressure, high temperature $\left(>825^{\circ} \mathrm{C}\right)$, and low $\mathrm{H}_{2} \mathrm{O}$ partial pressure $(<0.1 \%)[15]$. For instance, at $825^{\circ} \mathrm{C}$ and 0.05 $\% \mathrm{H}_{2} \mathrm{O}$, the oxidation rate is $2 \times 10^{-2} \mathrm{mg} / \mathrm{g}$.hr. An extrapolation to $500^{\circ} \mathrm{C}$ and $3 \% \mathrm{H}_{2} \mathrm{O}$ gives a oxidation rate of $10^{-4} \mathrm{mg} / \mathrm{g} . \mathrm{hr}$. This is quite small, and based on the exact tests conditions, the rate of oxidation may be acceptable for most facilities. $\mathrm{OH}$ formed from $\mathrm{H}_{2} \mathrm{O}$ photo-dissociation quickly recombines $(<10 \mathrm{~ms})$ thus does not pose a risk of facility oxidation

- $\mathrm{N}_{2} \mathrm{O}: \mathrm{N}_{2} \mathrm{O}$ has the advantage of remaining gaseous at up to a very high partial pressure. Data on oxidation of graphite by $\mathrm{N}_{2} \mathrm{O}$ and $\mathrm{NO}$ are given in [22] at temperature of $550^{\circ} \mathrm{C}$ and partial pressure of 5 to $20 \mathrm{kPa}$ (5 to $20 \%$ molar). By extrapolating to $500^{\circ} \mathrm{C}$ and $1 \% \mathrm{~N}_{2} \mathrm{O}$, a rate on the order of $10^{-2} \mathrm{mg} / \mathrm{g} \cdot \mathrm{hr}$ is estimated. This is higher than for $\mathrm{H}_{2} \mathrm{O}$, but again, the rate remains small and may be tolerable.

NO has higher reaction rate than $\mathrm{N}_{2} \mathrm{O}$ at similar conditions, but the NO partial pressure is only a small fraction of that of $\mathrm{N}_{2} \mathrm{O}$ in the experiment. For $0.1 \% \mathrm{NO}$ (conservative estimate) oxidation rate is also on the order of $10^{-2} \mathrm{mg} / \mathrm{g} \cdot \mathrm{hr}$.

\section{DEMONSTRATION OF $\mathrm{N}_{2} \mathrm{O}-\mathrm{MTV}$ IN AN IET FACILITY}

The present diagnostic was designed to be deployed in an IET of an HTGR: the HTTF at OSU to perform velocity measurements during a DCC. The implementation of this technique to the HTTF is reported in [18]. Sample results are presented here to illustrate the capabilities of MTV for gas reactor investigations. Detailed analysis of the results obtained in the facility will be presented in a subsequent paper.

The HTTF replicates a DCC by opening both hot and cold leg of the primary loop into a large reactor cavity simulation tank, which is a surrogate for the ambient gas surrounding the reactor. Velocity profiles are measured at the exit of the hot leg (a $300 \mathrm{~mm}$ diameter pipe) at a 


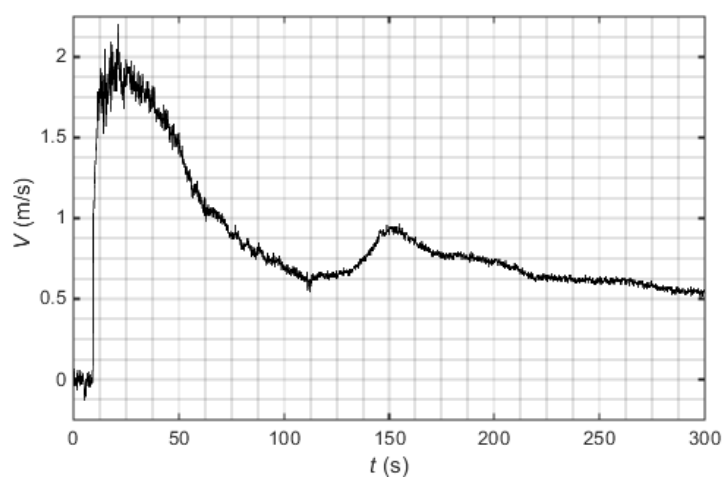

Fig. 6. Helium flow velocity (130 $\mathrm{mm}$ above the pipe centerline) as function of time for an isothermal DCC

frequency of $10 \mathrm{~Hz}$ for 30 minutes. In a DCC scenario, simulations predict helium to flow out of the reactor, and air (here nitrogen is used as a surrogate) to ingress into the reactor, in a buoyancydriven flow called a lock-exchange. For this experimental campaign, $\mathrm{N}_{2} \mathrm{O}$ (seeding at $0.5 \%$ ) was chosen because of: (i) lower risk of short-circuit to the electric heaters, (ii) better measurements precision for low speed flows, (iii) easy control of the seeding with pressure readings.

Figure 6 shows an example of velocity time evolution during an isothermal DCC. These results are the first detailed velocity data obtained in an IET with a laser spectroscopic technique and give insights into the complex flows associated with these events. The high measurement precision (down to $0.006 \mathrm{~m} / \mathrm{s}$ ) was crucial in these experiments because of the low velocities experienced in the HTTF $(<2 \mathrm{~m} / \mathrm{s})$. The laboratory investigation of the effect of temperature, pressure, and seed gas concentration and close integration between the teams enabled to select the best tracer and laser parameters for this study, and made this challenging in-situ measurement campaign a success.

\section{CONCLUSION}

The performance and applicability of MTV to gas flows present in thermal hydraulics have been investigated. While the study focused primarily on HTGR, the demonstrated application domain overlaps with conditions expected for containment studies and PWR reflood tests. Two gases $\left(\mathrm{H}_{2} \mathrm{O}\right.$ and $\left.\mathrm{N}_{2} \mathrm{O}\right)$ were extensively characterized as seed gases to probe flows over a large range of pressure, temperature, and velocity. Only small amounts $(<3 \%)$ of those innocuous seed gases 
are necessary to be adequately photo-dissociated in tracers that provide sufficient signal to noise ratio for the tests conducted here. HTV has been determined to operate satisfactorily at up to $100 \%$ steam concentration.

The applicability of both gases to gas reactors was discussed in term of ease of implementation, limitations, and risk to the facility. HTV was found to be preferable for moderate to high speed flows, in very large facilities, or in facilities where water vapor is already present. Its precision also increases with temperature. $\mathrm{N}_{2} \mathrm{O}-\mathrm{MTV}$ was found to be preferable for measuring low speed flows, and in facilities where condensation of water vapor could be problematic.

High precision measurements (down to a standard deviation of $0.004 \mathrm{~m} / \mathrm{s}$, the lowest value ever reported for MTV in gas) and large velocity dynamic range (up to 5,000:1, the largest known to the authors for laser velocimetry) were obtained in the laboratory. In-situ measurements were successfully conducted in an IET demonstrating the applicability and benefits of the MTV technique to HTGRs and thermal hydraulics in general.

\section{ACKNOWLEDGMENTS}

This project was supported by a DOE NEUP grant to Dr. Bardet.

\section{REFERENCES}

[1] R. Kapula, D. Uong, C. Zimmer, and D. Paladino, "PIV measurements in the vicinity of a steam sparger in the PANDA facility," Nuclear Engineering and Design (2017).

[2] L. Hochreiter, F.-B. Cheung, T. Lin, C. Frepoli, A. Sridharan, D. Todd, E. Rosal, and K. Tien, "Rod Bundle Heat Transfer Test Facility Test Plan and Design," NUREG/CR6975, US NRC (2010).

[3] J. Reyes, J. Groome, B. Woods, B. Jackson, and T. Marshall, "Scaling analysis for the high temperature Gas Reactor Test Section (GRTS)," Nuclear Engineering and Design, 240, 2, 397 (2010).

[4] C. Tropea, A. Yarin, and J. Foss, Springer Handbook of Experimental Fluid Mechanics, vol. 1, Springer Science \& Business Media (2007). 
[5] A. ElBaz and R. Pitz, " $\mathrm{N}_{2} \mathrm{O}$ molecular tagging velocimetry," Applied Physics B, 106, 4, $961(2012)$.

[6] P. Danehy, S. O’Byrne, A. Houwing, J. Fox, and D. Smith, "Flow-tagging velocimetry for hypersonic flows using fluorescence of nitric oxide," AIAA journal, 41, 2, 263 (2003).

[7] N. Parziale, M. Smith, and E. Marineau, "Krypton tagging velocimetry of an underexpanded jet," Applied optics, 54, 16, 5094 (2015).

[8] W. Lempert, N. Jiang, S. Sethuram, and M. Samimy, "Molecular tagging velocimetry measurements in supersonic microjets," AIAA journal, 40, 6, 1065 (2002).

[9] B. Stier and M. Koochesfahani, "Molecular tagging velocimetry (MTV) measurements in gas phase flows," Experiments in Fluids, 26, 4, 297 (1999).

[10] A. Noullez, G. Wallace, W. Lempert, R. Miles, and U. Frisch, "Transverse velocity increments in turbulent flow using the RELIEF technique," Journal of Fluid Mechanics, 339, 287 (1997).

[11] R. Pitz, J. Wehrmeyer, L. Ribarov, D. Oguss, F. Batliwala, P. DeBarber, S. Deusch, and P. Dimotakis, "Unseeded molecular flow tagging in cold and hot flows using ozone and hydroxyl tagging velocimetry," Measurement Science and Technology, 11, 9, $1259(2000)$.

[12] P. Danehy, B. Bathel, N. Calvert, A. Dogariu, and R. Miles, "Three-component velocity and acceleration measurement using FLEET," 30th AIAA Aerodynamic Measurement Technology and Ground Testing Conference, 2228 (2014).

[13] M. A. André, P. M. Bardet, R. A. Burns, and P. M. Danehy, "Characterization of hydroxyl tagging velocimetry for low-speed flows," Meas. Sci. Technol, 28, 085202, 085202 (2017).

[14] C. Hall, M. Ramsey, D. Knaus, and R. Pitz, "Molecular tagging velocimetry in nitrogen with trace water vapor," Measurement Science and Technology, Accepted (2017).

[15] L. Overholser and J. Blakely, "Oxidation of graphite by low concentrations of water vapor and carbon dioxide in helium," Carbon, 2, 4, 385 (1965). 
[16] B. Bathel, P. Danehy, C. Johansen, S. Jones, and C. Goyne, "Hypersonic Boundary Layer Measurements with Variable Blowing Rates Using Molecular Tagging Velocimetry," 28th Aerodynamic Measurement Technology, Ground Testing, and Flight Testing Conference including the Aerospace TEEE Days Forum, vol. 2886, 25-28 (2012).

[17] R. Pitz, M. Lahr, Z. Douglas, J. Wehrmeyer, S. Hu, C. Carter, K. Hsu, C. Lum, and M. Koochesfahani, "Hydroxyl tagging velocimetry in a supersonic flow over a cavity," Applied optics, 44, 31, 6692 (2005).

[18] M. A. André, R. A. Burns, P. M. Danehy, S. R. Cadell, B. G. Woods, and P. M. BARDET, "Development of $\mathrm{N}_{2} \mathrm{O}-\mathrm{MTV}$ for low-speed flow and in-situ deployment to an integral effect test facility," Experiments in Fluids, 59, 1, 14 (2018).

[19] J. Luque and D. Crosley, "LifBase: database and spectral simulation program (version 1.5)," SRI international report MP, 99, 009 (1999).

[20] D. G. Goodwin, H. K. Moffat, and R. L. Speth, "Cantera: An Object-oriented Software Toolkit for Chemical Kinetics, Thermodynamics, and Transport Processes," http://www. cantera.org (2017); 10.5281/zenodo.170284., version 2.3.0.

[21] L. Ribarov, J. Wehrmeyer, R. Pitz, and R. Yetter, "Hydroxyl tagging velocimetry (HTV) in experimental air flows," Applied Physics B, 74, 2, 175 (2002).

[22] Y.-C. BAK, "Reaction of NO and N 2 O gases with graphite in TGA," Korean Journal of Chemical Engineering, 15, 3, 336 (1998). 